\title{
Pyrethroid resistance in the major malaria vector Anopheles arabiensis from Gwave, a malaria-endemic area in Zimbabwe Givemore Munhenga1,2,3, Hieronymo T Masendu ${ }^{4}$, Basil D Brooke ${ }^{2,5}$, Richard H Hunt ${ }^{2,3}$ and Lizette K Koekemoer*2,5
}

Address: ${ }^{1}$ Department of Biological Sciences, University of Zimbabwe, P.O. Box MP 167, Mount Pleasant, Harare, Zimbabwe, ${ }^{2}$ Vector Control Reference Unit, National Institute for Communicable Diseases, NHLS, Private Bag X4, Sandringham, Johannesburg 2131, South Africa, ${ }^{3}$ School of Animal, Plant and Environmental Sciences, University of the Witwatersrand, Johannesburg, South Africa, ${ }^{4}$ Department of Public Health, P. Bag F26, Francistown, Botswana and ${ }^{5}$ Division of Virology and Communicable Diseases Surveillance, School of Pathology of the National Health Laboratory Service and the University of the Witwatersrand, Johannesburg, South Africa

Email: Givemore Munhenga - givemorem@nicd.ac.za; Hieronymo T Masendu - masenduron@yahoo.co.uk; Basil D Brooke - basib@nicd.ac.za; Richard H Hunt - maureenc@nicd.ac.za; Lizette K Koekemoer* - lizettek@nicd.ac.za

* Corresponding author

Published: 28 November 2008

Malaria Journal 2008, 7:247 doi:10.1 I86/I475-2875-7-247
Received: 23 July 2008

Accepted: 28 November 2008

This article is available from: http://www.malariajournal.com/content/7///247

(C) 2008 Munhenga et al; licensee BioMed Central Ltd.

This is an Open Access article distributed under the terms of the Creative Commons Attribution License (http://creativecommons.org/licenses/by/2.0), which permits unrestricted use, distribution, and reproduction in any medium, provided the original work is properly cited.

\begin{abstract}
Background: Insecticide resistance can present a major obstacle to malaria control programmes. Following the recent detection of DDT resistance in Anopheles arabiensis in Gokwe, Zimbabwe, the underlying resistance mechanisms in this population were studied.

Methods: Standard WHO bioassays, using $0.75 \%$ permethrin, $4 \%$ DDT, $5 \%$ malathion, $0.1 \%$ bendiocarb and $4 \%$ dieldrin were performed on wild-collected adult anopheline mosquitoes and $F_{\text {I }}$ progeny of An. arabiensis reared from wild-caught females. Molecular techniques were used for species identification as well as to identify knockdown resistance $(k d r)$ and ace-l mutations in individual mosquitoes. Biochemical assays were used to determine the relative levels of detoxifying enzyme systems including non-specific esterases, monooxygenases and glutathione-S-transferases as well as to detect the presence of an altered acetylcholine esterase (AChE).

Results: Anopheles arabiensis was the predominant member of the Anopheles gambiae complex. Of the $436 \mathrm{An}$. arabiensis females, $0.5 \%$ were positive for Plasmodium falciparum infection. WHO diagnostic tests on wild populations showed resistance to the pyrethroid insecticide permethrin at a mean mortality of $47 \%$ during February 2006 and a mean mortality of $68.2 \%$ in January 2008. DDT resistance (68.4\% mean mortality) was present in February 2006; however, two years later the mean mortality was $96 \%$. Insecticide susceptibility tests on $\mathrm{F}_{1}$ An. arabiensis families reared from material from two separate collections showed an average mean mortality of $87 \%(n=758)$ after exposure to $4 \%$ DDT and $65 \%(n=587)$ after exposure to $0.75 \%$ permethrin. Eight families were resistant to both DDT and permethrin. Biochemical analysis of $F_{1}$ families reared from collections done in 2006 revealed high activity levels of monooxygenase $(48.5 \%$ of families tested, $n=33, p<0.05)$, glutathione $S$ transferase $(25.8 \%$ of families tested, $n=31, p<0.05)$ and general esterase activity compared to a reference susceptible An. arabiensis colony. Knockdown resistance $(k d r)$ and ace- $\mathbb{I}^{R}$ mutations were not detected.

Conclusion: This study confirmed the presence of permethrin resistance in An. arabiensis populations from Gwave and emphasizes the importance of periodic and ongoing insecticide susceptibility testing of malaria vector populations whose responses to insecticide exposure may undergo rapid change over time.
\end{abstract}




\section{Background}

Malaria remains the most important parasitic disease in Zimbabwe causing significant mortality and morbidity despite concerted effort to control it. Approximately 50\% of the population live in malarious areas and are at risk of infection [1]. The greatest burden of malaria occurs in the low lying areas of the country [2,3], with children under five years of age, pregnant women and people living with HIV and AIDS being the most vulnerable [1].

Anopheles arabiensis is the main malaria vector in Zimbabwe $[4,5]$. Anopheles funestus and Anopheles merus occur sporadically and may be involved in malaria transmission in isolated incidences. The principal malaria intervention strategies in Zimbabwe include case management, vector control such as indoor residual spraying (IRS), and health education [1]. House spraying remains the Ministry of Health and Child Welfare's (MHCW) principal strategy for malaria vector control and malaria prevention. Indoor residual spraying started in 1949 with the use of benzene hexachloride (BHC) [6]. BHC was replaced with DDT after the discovery of a BHC resistant population of $A n$. arabiensis in the lowveld of the country [7]. The malaria control programme was briefly interrupted between 1976 and 1980 due to political unrest. Immediately after independence malaria vector control using DDT resumed. In order to manage bed bug resistance DDT and deltamethrin were used interchangeably for malaria vector and tsetse fly control from 1987 until 1991, when environmentalists succeeded in lobbying against its use. DDT has been re-introduced for adult vector control to complement the pyrethroid arsenal which includes deltamethrin, lambdacyhalothrin and alphacypermethrin.

Insecticide resistance can be defined as a reduction in the insecticide sensitivity of an insect population. This is reflected by repeated failure of an insecticide to achieve the expected level of control when used according to the recommendations for that pest species [8]. Insecticide resistance is generally mediated by behavioural, metabolic or physiological factors and usually results from one or more of three different mechanisms: reduction in insecticide penetration, an increased metabolism of insecticide by metabolic enzymes and or modification of the insecticide target site [9]. Insecticide resistance management becomes complicated if cross resistance or multiple insecticide resistance develops within a species. Multiple insecticide resistance occurs when insects develop resistance to several compounds, limiting the choice of insecticides that can be used.

Resistance management strategies require comprehensive information concerning malaria vector species composition in the area of interest, susceptibility to the insecticides proposed for use for their control and an understanding of the underlying resistance mechanisms [8]. Insecticide susceptibility monitoring has been confined to standard WHO bioassays conducted biannually by the National Institute of Health Research (formerly, Blair Research Laboratory). Despite the long-term use of pesticide in both agriculture and health, there have been few instances when resistance has been recorded. Two cases of resistance have been documented; one in Chiredzi involving BHC [7] and, more recently, DDT resistance in Gokwe [4,10]. An increase in malaria cases, especially in the 2003/4 season, has been attributed to the current socio-economic challenges facing the country resulting in difficulties in IRS coverage [1]. However, despite a marked increase in IRS and ITN coverage between 2004 and 2006, malaria cases, though declining, are still comparatively high. Therefore, factors other than socio-economic challenges might be playing a role. This paper reports on the vector status of An. arabiensis and its susceptibility to insecticides in Gokwe.

\section{Methods}

\section{Mosquito collections}

Anopheline mosquitoes were collected in Zimbabwe from Gwave $\left(17^{\circ} 55^{\prime} \mathrm{S}\right.$; $\left.28^{\circ} 41^{\prime} \mathrm{E}\right)$, a village in Gokwe South District, Midland's Province (Figure 1), in February 2006 and January 2008. Adult mosquitoes were captured between 1800 hrs and 2100 hrs using human-baited and cattle-bait net trapping [11] and cattle kraal collections using aspirators. Larvae were collected from stagnant pools at an artesian well and adjacent homesteads and were reared through to adults. Exit window traps were used to collect adults leaving houses [12]. Houses were searched between 0600 hrs and 1000 hrs in order to collect indoor-resting mosquitoes.

\section{Mosquito processing}

Female mosquitoes collected from the field and those reared from larvae were identified morphologically [13], and split into two cohorts. One cohort was used for WHO insecticide susceptibility assays and the other batch was kept alive to obtain $\mathrm{F}_{1}$ progeny. Dead specimens were desiccated on blue-indicator silica gel. Specimens were transported to the Vector Control Reference Unit (VCRU), National Institute for Communicable Diseases, Johannesburg, South Africa.

Wild-caught females were blood fed and separated into individual oviposition tubes. Families from each egg batch were reared separately, and 1-3 day old $F_{1}$ female progeny from large isofemale lines were divided into separate samples for bioassay and biochemical analyses. The specimens for biochemical assays were stored at $-70^{\circ} \mathrm{C}$.

Owing to a lack of statistical correlation between susceptibility to insecticide as determined by bioassay and 


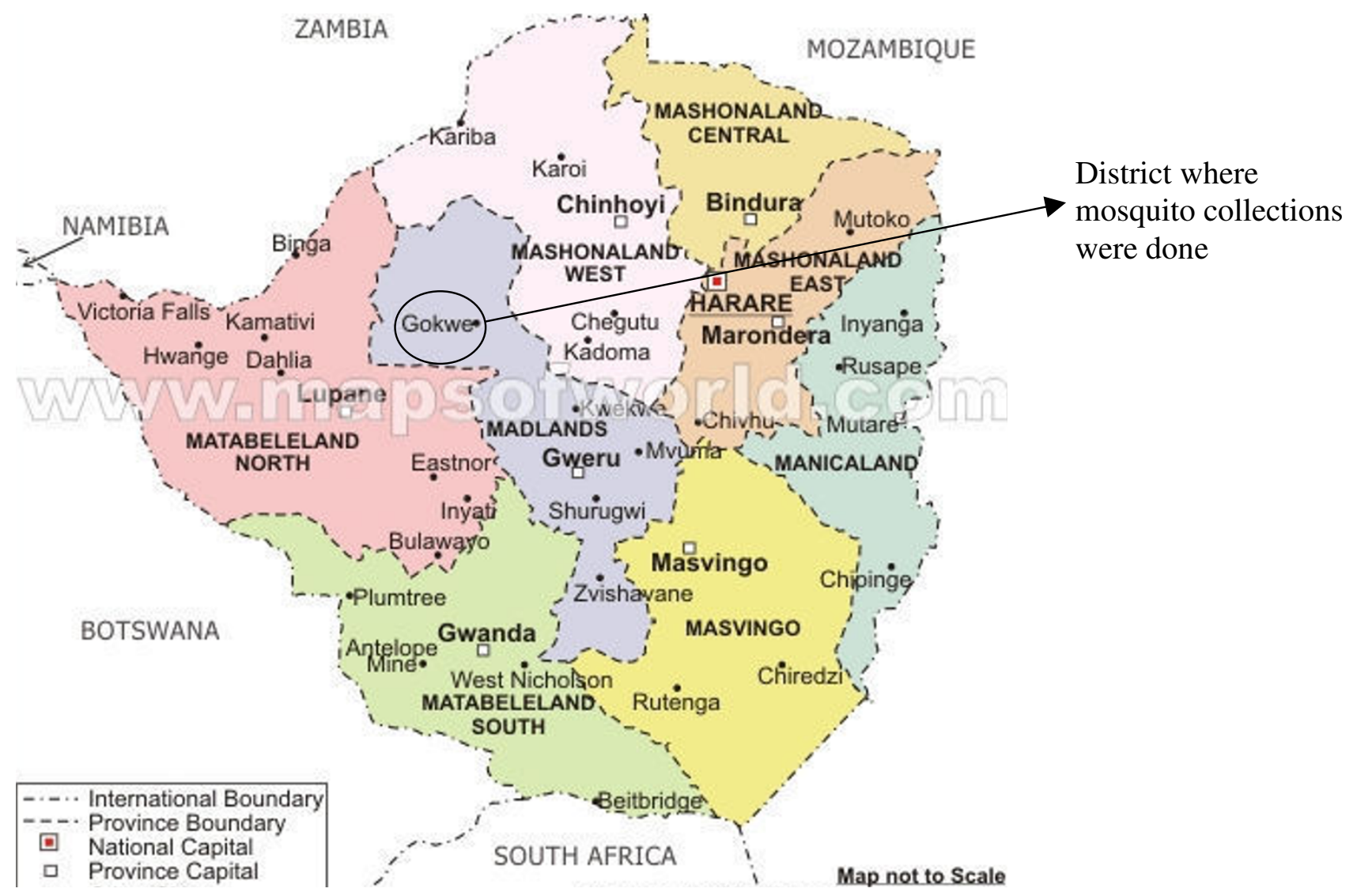

Figure I

Map of Zimbabwe showing study site location http://www.mapsofworld.com.

enzyme levels/activities as determined by biochemical assay in the 2006 collection, a second round of fieldwork was conducted in the same area in 2008. Isofemale lines were set up as described above. However, $\mathrm{F}_{1}$ adults showing survival to $4 \%$ DDT were pooled and the same was done for the survivors of $0.75 \%$ permethrin exposures. These resistant individuals were allowed to mate and their progeny, labelled $\mathrm{F}_{2}$, were subsequently used for biochemical analysis.

\section{Species-specific identification}

Wild caught adults were identified to species level. The An. gambiae complex sibling species were identified by PCR. [14]. Specimens belonging to the An. funestus group were identified using the multiplex PCR assay [15]. Samples which gave hybrid bands using the An. funestus multiplex PCR were further assayed with the Anopheles longipalpis multiplex PCR [16].

\section{Sporozoite detection}

The head and thoraces of female mosquitoes were tested for the presence of $P$. falciparum using ELISA [17]. A posi- tive control (recombinant $P$. falciparum) and negative control (un-infected female An. arabiensis from the Botha DeMellion insectary) were used. Results were scored both visually as well as photometrically at $405 \mathrm{~nm}$ using a plate reader (Multiskan RC vl. 5.0, Genesis version 3.03, Labsystems).

\section{Insecticide susceptibility tests}

The standard WHO susceptibility tests were conducted on field collected material using test-kits and insecticideimpregnated filter papers supplied by the WHO. Wild caught adults and 1-3 day old post-emergence adults reared from larval collections were exposed to 4\% DDT, $0.75 \%$ permethrin, $0.1 \%$ bendiocarb, $4 \%$ dieldrin, and $5 \%$ malathion for one hour. Each test consisted of 25 mosquitoes per tube with two controls. Two to six replicates were performed for each exposure set. For laboratory bioassays, 5 to 25, 3 day old $\mathrm{F}_{1}$ progeny were exposed to either $4 \%$ DDT or $0.75 \%$ permethrin. In all cases insecticide treated papers were tested; both prior to and after the exposures against a susceptible An. arabiensis colony (KGB strain) as quality assurance. 
For each bioassay, knockdown of mosquitoes was recorded after 60 minutes and final mortality scored after a 24 hour recovery period while supplied with $10 \%(\mathrm{w} / \mathrm{v})$ sugar solution. Insecticide susceptibility was classified according to the WHO criterion, which considers mortality above $98 \%$ and below $80 \%$ representative of susceptible and resistant populations, respectively, while the intermediates need further investigation [8].

\section{Molecular assay for knockdown resistance}

Mutations associated with knockdown resistance to pyrethroids and/or DDT were assayed in randomly selected bioassay survivors of wild caught females as well as those females where $F_{1}$ progeny showed resistance to both DDT and pyrethroids using the standard PCR assay $[18,19]$ Due to lack of repeatability the assay was adapted as follows: Three independent PCR assays were set up for each sample: the first contained the primers Agd 2 (5' AGACAAGGATGATGAACC $\left.3^{\prime}\right)$ and Agd 4 (5' CTGTAGTGATAGGAAATTTA 3') which amplify a 137-bp product for the insecticide susceptible allele; the second contained primers Agd 1 (5'ATAGATTCCCCGACCATG 3') and Agd 3 (5' AATTTGCATTACTTACGACA 3') for amplifying a 195-bp product associated with the West African resistant allele and the third contained primers Agd1 and Agd5 (5' TTTGCATTACTTACGACTG 3') which amplify a 195-bp product associated with the East African resistant allele [19]. PCR conditions were as previously described [20]. Reference standards were as follows: the positive control consisted of a DNA template from mosquitoes with known West African allele $(k d r-w)$ i.e SENNDDT (homozygous resistant, RR), while the negative control had KGB (homozygous susceptible, SS). No colony with the East African allele ( $k d r-e)$ was available. A DNAfree reaction mixture was used as a blank in all cases.

\section{Sequence analysis of the IIS6 domain}

The 293-bp fragment of the IIS6 domain spanning the $k d r$ mutation site was amplified using primers Agd1 and Agd2 in 38 mosquitoes inclusive of six specimens which showed cross resistance to both DDT and permethrin exposure. Amplicons were sequenced by Inqaba Biotechnical industries, South Africa. The DNA sequences were analysed with Lasergene software (DNASTAR version 7; SeqMan programme, Inc, Madison, WI). Basic Local Alignment Search Tool (BLAST) was used to confirm that the correct gene fragment had been amplified and sequenced [21].

\section{Ace- IR mutation}

A PCR diagnostic test was used to detect the presence of the G119S mutation in seven specimens which showed evidence of altered AChE during biochemical assays using the method described by Weill [22] with modifications.
Briefly, the ace $-1^{\mathrm{R}}$ gene was amplified by PCR with $\mathrm{F}$ ( $5^{\prime}$ CCGGGCGCGACCATGGAA 3') and R (5' ACGATCACGTTCTCCTCCGA 3') oligonucleotide primers. The reaction was performed in $12.5 \mu$ l volume containing $1.25 \mu \mathrm{l}$ of $10 \times$ buffer, $200 \mu \mathrm{M}$ dNTP, $0.1 \mathrm{U}$ Taq polymerase, 10 pmol of each primer and 1-10 ng of extracted DNA. PCR cycling conditions included an initial denaturation step at $94^{\circ} \mathrm{C}$ for 2 mins, followed by 40 cycles of: denaturation at $94^{\circ} \mathrm{C}$ for 30 secs, annealing at $53^{\circ} \mathrm{C}$ for 30 secs and primer extension at $72^{\circ} \mathrm{C}$ for $1 \mathrm{~min}$. These cycles were followed by a final auto extension at $72^{\circ} \mathrm{C}$ for 5 mins. Five microlitres of the amplicons were electrophoresed on a $2.5 \%$ agarose gel and visualized under an ultraviolet transilluminator to confirm whether the expected band size had been amplified while the remainder of each amplicon was sent to Inqaba Biotechnical Industries, South Africa for sequencing. Sequences were analysed with Lasergene software as previously outlined. Controls consisted of An. arabiensis individuals from families which did not show AChE activity during biochemical assays.

\section{Biochemical analysis}

Levels of monooxygenase, non-specific esterase, glutathione-S-transferase (GST) and altered acetylcholine esterase (AChE) were assayed from individual 1-3 day old post emergence mosquitoes, using cohorts of 47 mosquitoes per microtitre plate [23]. From each family, 6-10 female mosquitoes were assayed with several families/ plate in comparison to 11 specimens of a susceptible An. arabiensis (KGB) strain. For $\mathrm{F}_{2}$ progeny, 24 females were assayed on the same plate as 24 susceptible colony An. arabiensis. Mean enzyme activities measured as optical densities at specified wavelengths were compared between the families and samples from the susceptible reference colony using two sample t-tests of means following adjustment for total protein content (STATISTIX 7.0; Tallahassee, FL, USA). Significance in difference was determined at $\mathrm{p}<0.05$.

\section{Results \\ Mosquito collections}

In total, 924 anophelines belonging to four different taxa were collected and positively identified (Table 1). Three members of the An. gambiae complex occurred in sympatry. Anopheles arabiensis was the predominant species contributing $73.4 \%$ to the total collection, while An. merus (14\%) and Anopheles quadriannulatus (11.4\%) were the other species collected. Other taxa collected included members of the Anopheles squamosus group (0.6\%), Anopheles coustani $(0.3 \%)$ and An. funestus group (0.2\%). Two specimens morphologically identified as An. funestus were subsequently shown to be An. longipalpis following the multiplex PCR assay [16,24] (Figure 2). 
Table I: Summary of anophelines caught and positively identified in Gwave (MBN = "man-baited net trap" and N = Sample size)

\begin{tabular}{|c|c|c|c|c|c|c|c|c|}
\hline Collection period & Collection Method & $\mathrm{N}$ & An. arabiensis & An, quadriannulatus & An. merus & An. longipalpis & An. squamosus & An. coustani \\
\hline \multirow[t]{3}{*}{ February, 2006} & Cattle kraal & 511 & 422 & 66 & 12 & 2 & 6 & 3 \\
\hline & Larval & 43 & 36 & 6 & 1 & 0 & 0 & 0 \\
\hline & $\mathrm{MBN}$ & 22 & 12 & 1 & 9 & 0 & 0 & 0 \\
\hline \multirow[t]{3}{*}{ January, 2008} & Cattle bait & 181 & 101 & 7 & 73 & 0 & 0 & 0 \\
\hline & Larval & 144 & 85 & 25 & 34 & 0 & 0 & 0 \\
\hline & Window exit & 23 & 23 & 0 & 0 & 0 & 0 & 0 \\
\hline Totals (\%) & & 924 & 679(73.4) & $105(11.4)$ & $129(14.0)$ & $2(0.2)$ & $6(0.6)$ & $3(0.3)$ \\
\hline
\end{tabular}

\section{Mosquito infectivity}

A total of 530 anophelines were assayed for infection with P. falciparum sporozoites (436 An. arabiensis, 73 An. quadriannulatus and 21 An. merus). All were negative except for two infected An. arabiensis giving an overall infection rate of $0.5 \%$ for this species. Both specimens were collected using man baited net traps (MBN) during 2006.

\section{Insecticide susceptibility tests}

Table 2 shows the results of standard WHO susceptibility tests against wild caught mosquitoes. Anopheles arabiensis is resistant to permethrin, but completely susceptible to malathion, dieldrin and bendiocarb. Samples collected in February 2006 showed high resistance to DDT (68.4\%) while those collected in January 2008 showed the population to be almost susceptible (96\%). Exposure to $0.75 \%$ permethrin of families reared from An. arabiensis collected during 2006 showed evidence of resistance in 21 families $(56.8 \%, \mathrm{n}=37)$ with mortalities ranging from $0 \%$ to $100 \%$ with an average of $69.8 \%$ across the families. Permethrin exposures of $\mathrm{F}_{1}$ families reared from samples collected in January 2008 showed resistance in 11 families $(78.6 \%, \mathrm{n}=14)$. Final mortalities following exposure to $4 \%$ DDT ranged from $28.6 \%$ to $100 \%$. There was evidence of resistance in 16 families $(25.4 \%, \mathrm{n}=59)$ in samples collected in 2006 and 2 families $(14.3 \%, \mathrm{n}=14)$ in samples collected in 2008. Table 3 summarizes results of families exposed to both insecticides. Eight families (six collected

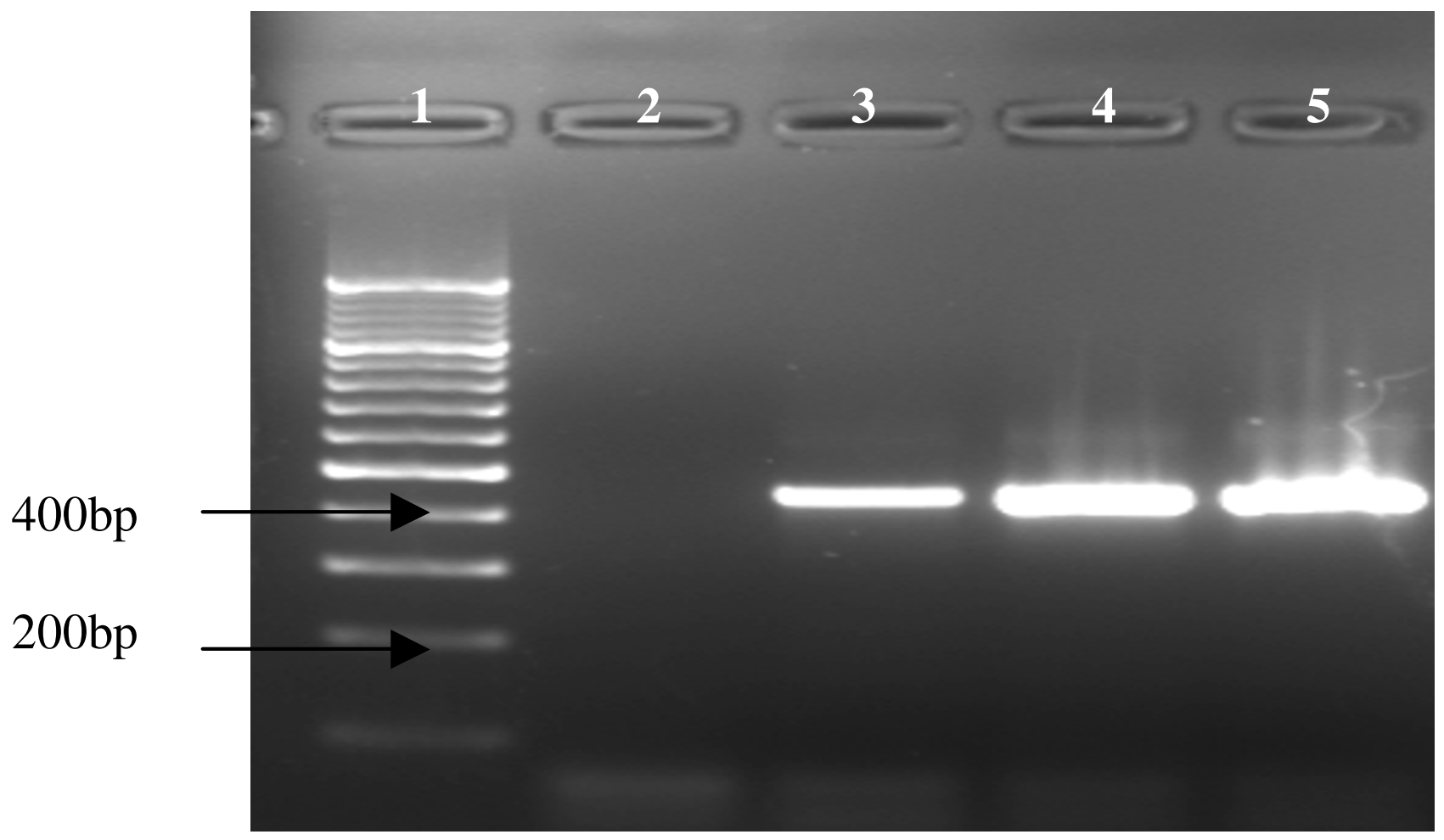

\section{Figure 2}

Multiplex PCR to identify An. longipalpis [16]. Lane I: I Kb molecular weight marker, Lane 2: Negative control, Lane 3: An. longipalpis Type C (positive control), Lane 4 and 5: An. longipalpis Type C. 
Table 2: Field susceptibility tests carried out on An. arabiensis caught in Gwave in February, 2006 and January, 2008 (* Resistant according to WHO criteria).

\begin{tabular}{|c|c|c|c|c|c|c|c|c|c|c|}
\hline \multirow[b]{3}{*}{ Collection period } & \multicolumn{10}{|c|}{ Insecticides } \\
\hline & \multicolumn{2}{|c|}{$\begin{array}{l}\text { 0.75\% Permethrin } \\
\text { (Pyrethroid) }\end{array}$} & \multicolumn{2}{|c|}{$\begin{array}{c}4 \% \text { DDT } \\
\text { (Organochlorine) }\end{array}$} & \multicolumn{2}{|c|}{$\begin{array}{l}\text { 4\% dieldrin } \\
\text { (Cyclodienes) }\end{array}$} & \multicolumn{2}{|c|}{$\begin{array}{l}0.1 \% \text { bendiocarb } \\
\text { (Carbamate) }\end{array}$} & \multicolumn{2}{|c|}{$\begin{array}{c}5 \% \text { malathion } \\
\text { (Organophosphates) }\end{array}$} \\
\hline & Total (n) & (\%) mort & Total (n) & (\%) mort & Total (n) & (\%) mort & Total (n) & (\%) mort & Total (n) & (\%) mort \\
\hline February, 2006 & 87 & $47^{*}$ & 110 & $68.4^{*}$ & 37 & 100 & 40 & 100 & 52 & 100 \\
\hline January, 2008 & 66 & $68.18^{*}$ & 75 & $96 *$ & - & - & 100 & 98.9 & - & - \\
\hline
\end{tabular}

in 2006 and two collected in 2008) showed resistance to both DDT and permethrin.

\section{Detection of kdr alleles}

Molecular analysis of 54 individuals by allele-specific PCR showed the presence of both the East and West African $k d r$ mutations. All three genotypes determined by $k d r$ PCR (RR, RS and SS) were detected in insecticide bioassay survivors as well as susceptibles. However, sequence analysis of the region spanning the $k d r$ mutation in 38 of these individuals showed a complete absence of both the "LeuPhe" and "Leu-Ser" $k d r$ mutations.

\section{Ace- $I^{R}$ mutation}

The ace- $I^{R}$ mutation was not detected in any of the seven specimens sequenced. Therefore, the reduced sensitivity of AChE activity to propoxur inhibition as detected biochemically in some families cannot be attributed to the single point mutation G119S (gene ace-I) [22].

\section{Biochemical assays}

Adults reared from $\mathrm{F}_{1}$ progeny were biochemically analysed for comparative enzyme levels. Figure 3 shows the average levels of GST, monooxygenase and esterase activities for $\mathrm{F}_{1}$ progeny in An. arabiensis families. Eight families $(25.8 \%, \mathrm{n}=31)$ showed significantly higher levels of GST activity $(P<0.05)$ compared to the reference KGB sample. Average levels of non-specific esterase activity/ family (using $\alpha$-naphthyl acetate as substrate) indicated nine families $(27.3 \%, \mathrm{n}=33)$ with significantly higher levels of esterase activity $(\mathrm{p}<0.05)$ than their corresponding KGB control samples. There was a significant correla-

Table 3: WHO insecticide susceptibility test results on I-3 day old $F_{1}$ An. arabiensis reared from females collected from Gwave village in 2006 and 2008. Results expressed as \% mortality $24 \mathrm{hr}$ post exposure. (* indicate Families showing cross resistance to DDT and permethrin, Fam $=$ Family)

\begin{tabular}{|c|c|c|c|c|c|c|c|c|c|c|c|c|c|c|}
\hline \multicolumn{15}{|c|}{ February 2006} \\
\hline \multirow[b]{2}{*}{ Fam. } & \multicolumn{2}{|c|}{ 4\% DDT } & \multicolumn{2}{|c|}{$0.75 \%$ permethrin } & \multirow[b]{2}{*}{ Fam. } & \multicolumn{2}{|c|}{ 4\% DDT } & \multicolumn{2}{|c|}{$0.75 \%$ permethrin } & \multirow[b]{2}{*}{ Fam. } & \multicolumn{2}{|c|}{$4 \%$ DDT } & \multicolumn{2}{|c|}{$0.75 \%$ permethrin } \\
\hline & (n) & $\%$ mort & (n) & $\%$ mort & & $(n)$ & $\%$ mort & $(n)$ & $\%$ mort & & (n) & $\%$ mort & (n) & $\%$ mort \\
\hline $27^{*}$ & 7 & 28.6 & 13 & 53.9 & 82 & 9 & 100 & 8 & 63.6 & 113 & 10 & 60 & 4 & 100 \\
\hline 37 & 11 & 72.7 & 11 & 81.8 & 84 & 10 & 90 & 11 & 54.5 & $118 *$ & 9 & 66.7 & 6 & 16.7 \\
\hline 38 & 9 & 100 & 12 & 66.7 & 85 & 13 & 100 & 10 & 50 & 120 & 10 & 100 & 10 & 100 \\
\hline 46 & 5 & 100 & 8 & 0 & 90 & 8 & 100 & 10 & 100 & 135 & 11 & 100 & 10 & 80 \\
\hline 48 & 10 & 100 & 10 & 70 & $94^{*}$ & 8 & 62.5 & 9 & 44.4 & 139 & 11 & 100 & 6 & 66.7 \\
\hline 53 & 11 & 100 & 12 & 100 & 95 & 13 & 69.2 & 6 & 100 & $144^{*}$ & 14 & 78.6 & 15 & 66.7 \\
\hline 57 & 7 & 100 & 15 & 46.7 & 97 & 11 & 81.8 & 13 & 92.3 & 149 & 11 & 54.6 & 10 & 100 \\
\hline $64^{*}$ & 12 & 33.3 & 8 & 50 & 101 & 9 & 100 & 11 & 18.2 & 156* & 13 & 69.2 & 11 & 45.5 \\
\hline 66 & 7 & 100 & 11 & 45.5 & 103 & 9 & 100 & 10 & 90 & 169 & 10 & 100 & 10 & 60 \\
\hline 74 & 12 & 16.7 & 12 & 100 & 104 & 8 & 87.5 & 12 & 50 & 166 & 8 & 100 & 12 & 83.3 \\
\hline 77 & 14 & 100 & 11 & 63.6 & 108 & 7 & 100 & 8 & 100 & 178 & 7 & 100 & 9 & 55.6 \\
\hline 80 & 10 & 100 & 10 & 90 & 111 & 11 & 100 & 11 & 72.7 & 180 & 9 & 100 & 9 & 100 \\
\hline \multicolumn{15}{|c|}{ January 2008} \\
\hline & \multicolumn{2}{|c|}{$4 \%$ DDT } & \multicolumn{2}{|c|}{$0.75 \%$ permethrin } & & \multicolumn{2}{|c|}{$4 \%$ DDT } & \multicolumn{2}{|c|}{$0.75 \%$ permethrin } & & \multicolumn{2}{|c|}{$4 \%$ DDT } & \multicolumn{2}{|c|}{$0.75 \%$ permethrin } \\
\hline Fam. & (n) & $\%$ mort & (n) & $\%$ mort & Fam. & (n) & $\%$ mort & $(n)$ & $\%$ mort & Fam. & (n) & $\%$ mort & (n) & $\%$ mort \\
\hline 654 & 11 & 100 & 15 & 93.33 & 740 & 16 & 100 & 18 & 72.2 & 821 & 12 & 100 & 15 & 53.3 \\
\hline 681 & 14 & 100 & 13 & 61.54 & 755 & 13 & 100 & 20 & 55 & 854 & 15 & 100 & 15 & 100 \\
\hline 682* & 25 & 74 & 19 & 68.23 & 769 & 23 & 100 & 21 & 52.4 & 856 & 10 & 100 & 8 & 50 \\
\hline 712 & 12 & 100 & 15 & 40 & $771 *$ & 10 & 78 & 14 & 14.3 & 858 & 15 & 100 & 15 & 100 \\
\hline 738 & 11 & 100 & 10 & 20 & 808 & 20 & 100 & 17 & 35.3 & & & & & \\
\hline
\end{tabular}



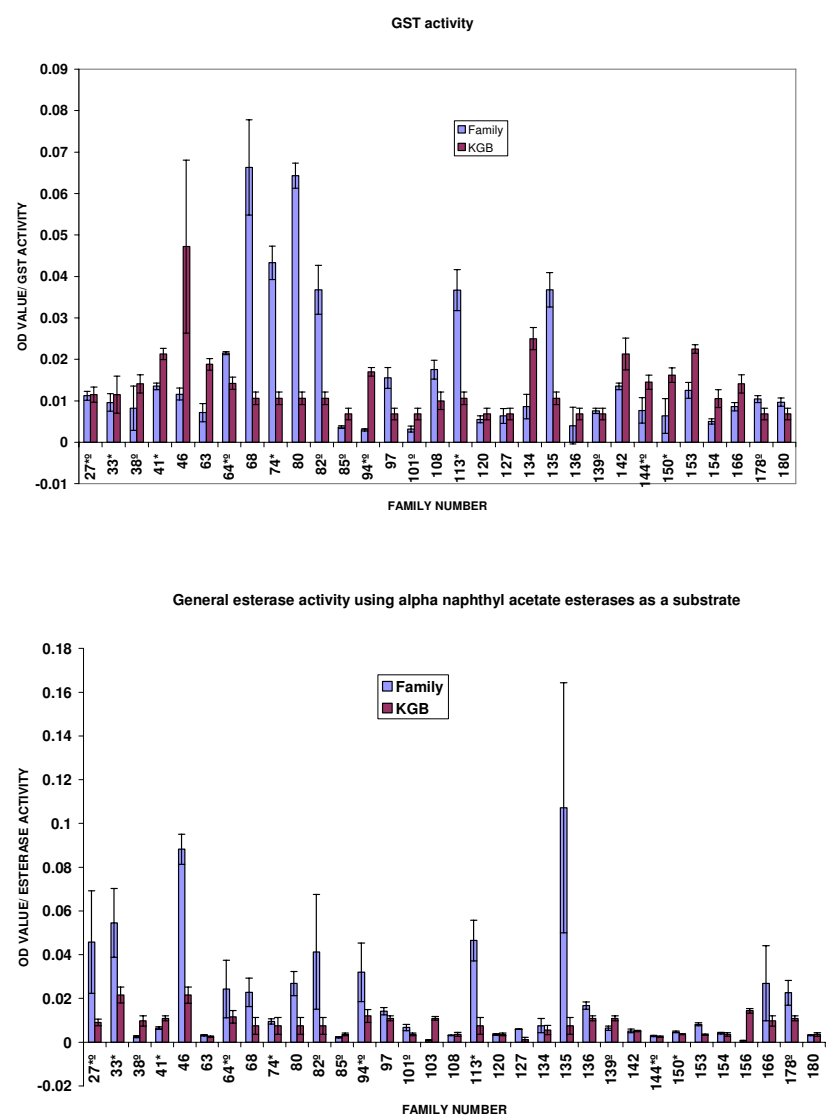
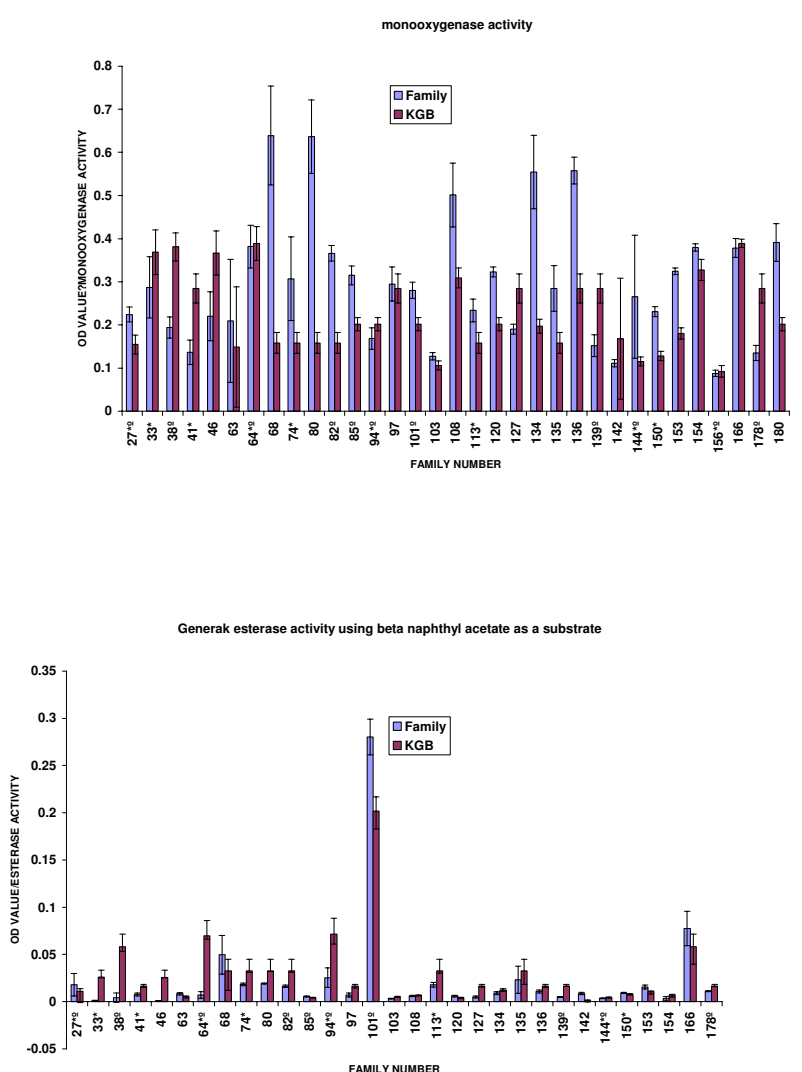

Figure 3

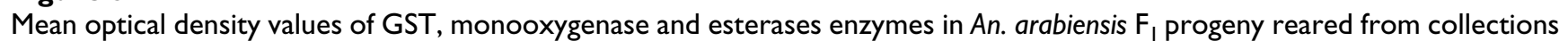
done in 2006, by family, and corresponding activity for susceptible An. arabiensis (KGB) samples assayed simultaneously.

tion between esterase level and permethrin as well as DDT bioassay mortality data $(\mathrm{p}<0.05)$. Assays using $\beta$-naphthyl acetate as a substrate showed that only two families $(6.5 \%, \mathrm{n}=31)$ had significantly increased esterase activity. Levels of monooxygenase were significantly elevated in 16 families $(48.5 \%, \mathrm{n}=33)$. There was no significant correlation between monooxygenase activity and bioassay (permethrin and DDT) mortality data ( $p>0.05)$. Figure 5 shows the mean percentage propoxur inhibition of AChE using $\mathrm{F}_{1}$ progeny reared from the 2006 collections. Only seven families $(20.6 \%, \mathrm{n}=34)$ showed evidence of an altered AChE based on the criterion that enzyme inhibition of less than $70 \%$ indicates significantly reduced AChE sensitivity to propoxur [23].

The lack of statistical correlation between the bioassay and biochemical assays may have been due to the presence of susceptible individuals in each family resulting in the masking of the elevated enzyme levels. It was therefore decided to characterize the resistance mechanism further by allowing $\mathrm{F}_{1}$ bioassay survivors from the 2008 collec- tions to mate and produce $\mathrm{F}_{2}$ progeny, thereby preventing the need to colonise An. arabiensis and then artificially select for either pyrethroid or DDT resistance. The $\mathrm{F}_{2}$ generation would then theoretically be composed of resistant individuals and would reduce the masking effect of susceptible siblings. Biochemical analysis on $\mathrm{F}_{2}$ adults showed a significant elevation in monooxygenase, $(\mathrm{p}<$ $0.05)$ activity when compared to the susceptible reference colony (KGB) (Figure 4). There was also a marked increase in monooxygenase activity in the $\mathrm{F}_{2}$ cohorts compared to the $\mathrm{F}_{1}$ progeny.

\section{Discussion}

Malaria vector composition and distribution in Zimbabwe is well documented. In Gokwe, members of the $A n$. gambiae complex, predominantly An. arabiensis, have been implicated as the main vectors $[4,5]$. This study confirms An. arabiensis as the main malaria vector in Gwave. Anopheles arabiensis predominated over all the other sibling species in wild collections and was the only species found to be infected with the malaria parasite $P$. falciparum. The 

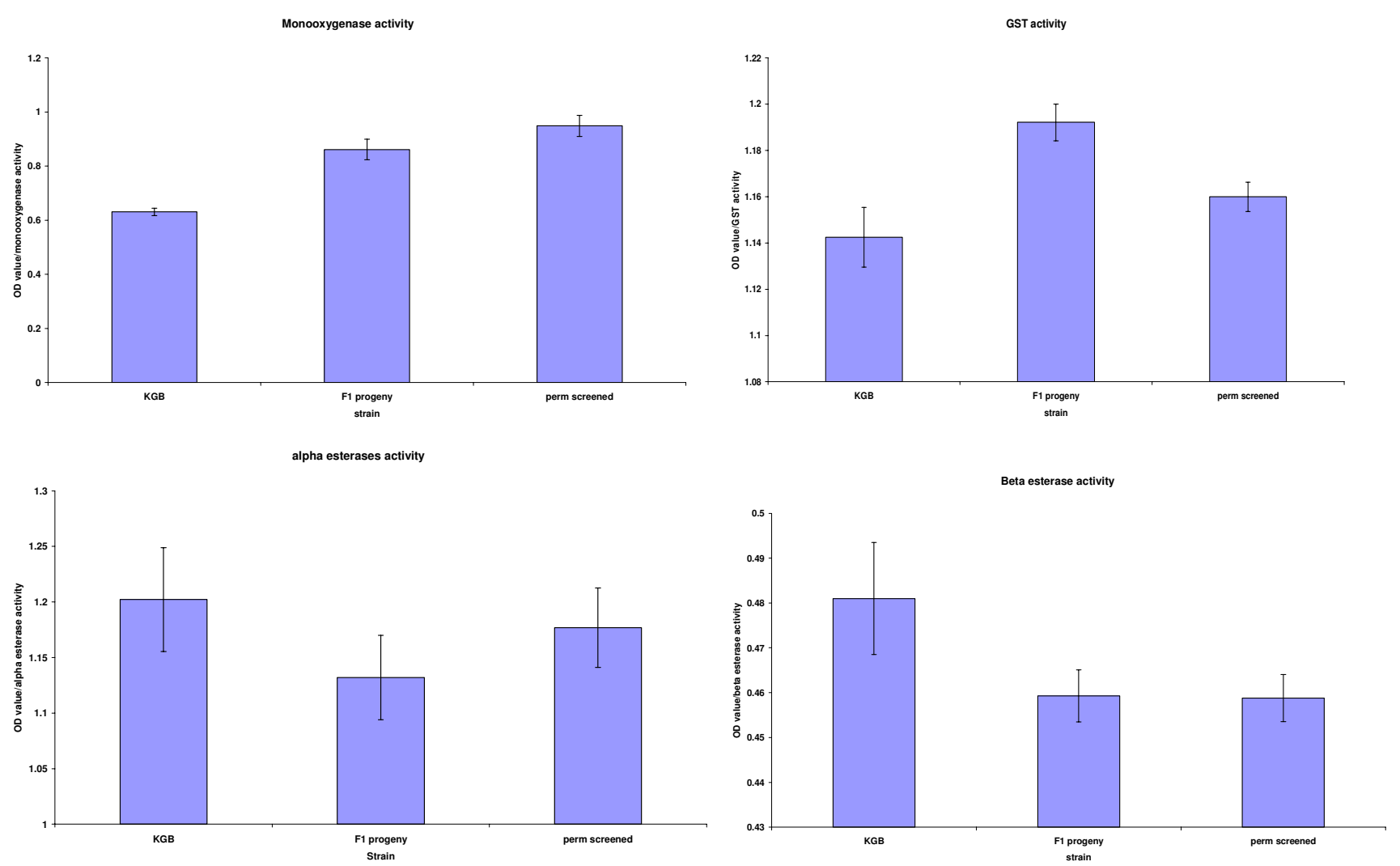

Figure 4

Mean optical density values of GST, monooxygenase and esterases enzymes of $F_{1}$ and $F_{2}$ An. arabiensis progeny (perm screened) reared from collections done in 2008 and corresponding activity for susceptible An. arabiensis (KGB) samples assayed simultaneously.

low infectivity rate detailed here could be attributed to the timing of mosquito collections as malaria transmission peaks from mid February to late April in Zimbabwe [5]. The presence of An. longipalpis Type $\mathrm{C}$ in our collections, which we had morphologically mis-identified as $A n$. funestus, highlights the need for molecular species identification, especially where malaria vectors occur in sympatry with closely related non-vectors.

The insecticide susceptibility status of malaria vectors in Zimbabwe remains unclear. Some reports detail complete susceptibility to insecticides in Gokwe $[25,26]$ whilst another reported DDT resistance from the same area [4]. In order to understand the resistant mechanisms that might be involved, insecticide susceptibility, molecular and biochemical assays were used. The importance of continual insecticide resistance monitoring is clearly illustrated by the difference in susceptibility to DDT between the two collection periods. Patterns of insecticide resistance may vary considerably in time and it is therefore important to have an active entomological surveillance system as part of a malaria vector control programme. From the surveys detailed here, resistance to permethrin was consistently recorded while the population showed complete susceptibility to organophosphates and carbamates.

Elevated GST activity is often associated with DDT resistance in insects where resistance is achieved by dehydrochlorination of DDT to DDE [27]. In data presented here, GST activity was significantly elevated in eight families reared from wild caught females, providing a strong candidate mechanism for production of the resistance phenotype. Anopheles arabiensis resistance to DDT in this locality was first reported during a survey carried out between 1999 and 2002 [4], and was attributed to high usage of organochlorines by villagers as well as a long history of DDT usage in this area. DDT was used as far back as 1970 when it was used for both tsetse fly and malaria vector control [28]. Currently DDT is being used interchangeably with pyrethroid insecticide $\left(\operatorname{Icon}^{\circledR}\right)$. The Icon ${ }^{\circledR}$ might have reduced the selective pressure imposed by DDT resulting 


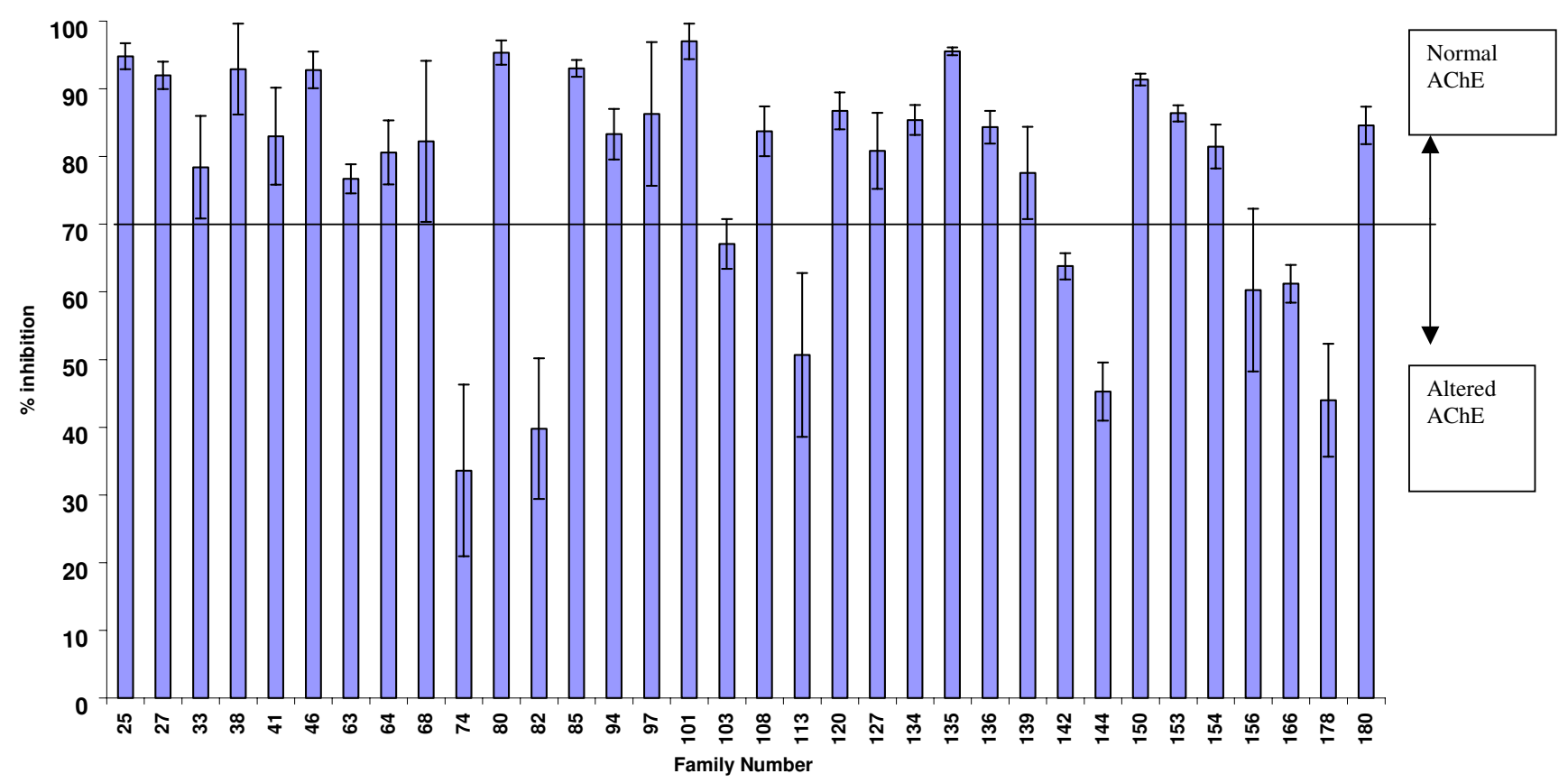

Figure 5

Mean acetylcholinesterase percentage inhibition by propoxur in $F_{1}$ progeny of An. arabiensis reared from wild-caught females collected in Gwave during February 2006.

in an increase in DDT susceptible individuals in the specimens collected during 2008. This probably explains the variation in DDT susceptibility.

Pyrethroid resistance is often mediated by monooxygenase detoxification. Resistance to permethrin in the samples tested here may be attributed to increased levels of monooxygenase titres as recorded in the $\mathrm{F}_{1}$ progeny of 16 wild caught An. arabiensis females. Selection for permethrin resistance in the $F_{1}$ progeny was followed by an increase in monooxygenase as well as general esterase activity. The combined effect of elevated monooxygenase and esterase activity in permethrin resistant Anopheles mosquitoes has previously been reported $[29,30]$.

This is the first instance of pyrethroid resistance recorded in a malaria vector species in the Gokwe district. Such resistance has serious implications for malaria control, considering that deltamethrin and lamdacyhalothrin are the main insecticides currently being used for vector control by the Zimbabwe National Malaria Control Programme. These insecticides are also recommended by WHO for vector control, especially for bed net treatment. The development of resistance may be due to selection pressure from agricultural use of pyrethroids. For example, the local community uses pyrethroids for controlling cotton pests. A survey from 1999 showed the high rank of pyrethroids among the insecticides used in Gokwe $[4,10]$.
Residues of pyrethroids sprayed on cotton and rice crops have been suggested as the source of selection favouring the emergence of pyrethroid resistance [31,32].

The occurrence of resistance of both DDT and permethrin observed during 2006 is a strong indicator of the presence of target site insensitivity. Target site insensitivity, sometimes known as knock-down resistance $(k d r)$, has been closely associated with cross-resistance to DDT and pyrethroids in malaria vectors $[19,20,33,34]$. Results presented here show a complete absence of both East and West African $k d r$ mutations in those families showing resistance to both DDT and pyrethroids. It is conceivable that alternative amino acid substitutions in the An. arabiensis sodium channel gene may be responsible for resistance to DDT and pyrethroids. Based on the discrepancy between PCR and sequence data this study confirms the widely held view that mutation-specific PCR assays developed to detect single nucleotide polymorphisms are often difficult to optimize and may not be as reliable as other methods [35,36]. The inconsistent PCR results obtained after repeating the assay using the same samples under similar conditions as well as the disparity between sequence data and PCR results has previously been reported from this laboratory. During an investigation of pyrosequencing as an alternative for detecting $k d r$ mutations it was shown that PCR results did not correlate with either sequence or pyrosequence data (Vezenegho, 
unpublished data). A poor correlation between PCR and sequence data has also been demonstrated for An. arabiensis in Sudan [37].

\section{Conclusion}

This study confirmed the presence of DDT and permethrin resistance in An. arabiensis in Gokwe. Both resistance phenotypes are most likely based on metabolic detoxification. The way forward is careful consideration on the use of insecticides. A mosaic system of insecticide application or rotational use of insecticides to slow the spread of DDT and pyrethroid resistance is suggested. We also recommend regular monitoring of resistance using WHO bioassays.

\section{Competing interests}

The authors declare that they have no competing interests.

\section{Authors' contributions}

GM carried out field work, species-specific identification, ELISAs, biochemical assays, interpretation of all results and wrote the first and subsequent drafts of the manuscript.

HTM was involved in project design and field work. BDB helped interpret the results of the biochemical assays and contributed to the writing of the manuscript. RHH was involved in field work, morphological identification of anophelines and provided comments on the manuscript. LLK conceived the project, oversaw its implementation, carried out laboratory bioassays, assisted with species identification and contributed to the subsequent writing of the manuscript.

\section{Acknowledgements}

We thank Prof R.A. Wirtz (CDC Entomology Branch, Atlanta, GA) for supplying $P$. falciparum-positive controls and monoclonal antibody $P$. falciparum 2A IO for indirect ELISA. We are grateful to Dr. S. Mutambu of the National Institute of Health Research (Zimbabwe) for allowing us to use their facilities and to Mr. L. Nzira and Gokwe District Hospital officials for their technical assistance during mosquito collections. We also thank Dr. P. Chinwada of the University of Zimbabwe for his supervisory role during the duration of the project.

This investigation received financial support under the Multinational Initiative on Malaria (MIM) project A 40036 through the UNICEF/UNDP/World Bank/WHO Special Programme for Research and Training in Tropical Diseases (TDR) to LLK. This work was also partially funded by the South African Medical Research Council and the National Health Laboratory Service Research Trust to LLK.

\section{References}

I. Midzi S, Teveredzi V, Mudyiradima R, Chihanga S, Netsa M, Mugove AT, Charimari L, Pasipamire J, Mutambu S, Kibassa C, Ngwenya N, Gausi K, Banda J, Mukelabai K, O'Connell T, Root G: Zimbabwe Roll Back Consultative Mission (Reaping): Essential actions to support the attainment of the Abuja Targets Zimbabwe RBM Country Consultative Mission Final report; 2004.
2. Crees MJ, Mhlanga C: Malaria prevalence in Zimbabwe and parasite survey of 1983. Zim Sci News 1985, 19:1 I4-117.

3. Taylor P, Mutambu SL: A review of the malaria situation in Zimbabwe with special reference to the period I972-I98I. Trans $R$ Soc Trop Med Hyg 1986, 80: I2-19.

4. Masendu HT, Hunt RH, Koekemoer LL, Brooke BD: Spatial and temporal distributions and insecticide susceptibility of malaria vectors in Zimbabwe. Afr Entomol 2005, I3(suppl I):25-34.

5. Mpofu SM: Seasonal vector density and disease incidence pattern in an area of Zimbabwe. Trans $R$ Soc Trop Med Hyg 1985, 79:169-175.

6. Zahar AR: The vector bionomics in the epidemiology and control of malaria Part I. In The WHO African Region and the Southern WHO Eastern Mediterranean Region World Health Organization Geneva; 1985

7. Green CA: Malaria epidemiology and anopheline cytogenetics. In Cytogenetics and Genetics of Vectors Edited by: Pal R, Kitzmiller JB, Kanda T. Elsevier Biomedical, Amsterdam; 1982:21-29.

8. World Health Organization: Report of the WHO informal consultation. Test procedures for insecticide resistance monitoring in malaria vectors, bioefficacy and persistence of insecticides on treated surfaces. Geneva 1998.

9. Hemingway J, Hawkes NJ, McCarroll L, Ranson H: The molecular basis of insecticide resistance in mosquitoes. Insect Biochem Mol Biol 2004, 34: 179-184.

10. Masendu HT: Vector mosquitoes and their significance in malaria epidemiology and control in Zimbabwe PhD Thesis University of Witwatersrand, South Africa; 2004: I- 10.

II. Mpofu SM, Masendu HT: Description of a baited trap for sampling mosquitoes. J Am Mosq Control Assoc 1986, 2:363-365.

12. Service MW: Mosquito ecology: Field sampling methods. Applied Science Publishers LTD, London; 1976.

13. Gillies MT, Coetzee M: A supplement to the Anophelinae of Africa south of the Sahara (Afro tropical Region). South African Institute for Medical Research 1987, 55:

14. Scott JA, Brogdon WG, Collins FH: Identification of single specimens of the Anopheles gambiae complex by the polymerase chain reaction. Am J Trop Med Hyg 1993, 49:520-529.

15. Koekemoer LL, Kamau L, Hunt RH, Coetzee M: A cocktail polymerase reaction assay to identify members of the Anopheles funestus (Diptera: Culicidae) group. Am J Trop Med Hyg 2002, 66:804-8II.

16. Koekemoer LL, Misiani EA, Hunt RH, Kent RJ, Norris DE, Coetzee M: Cryptic species within Anopheles longipalpis from southern Africa and phylogenetic comparison with members of the An. funestus group. Bull Entomol Res :I-9.

17. Wirtz RA, Zavala F, Charoenvit Y, Campell GH, Burkot TR, Schneider I, Esser KM, Beaudoin RL, Andre RG: Comparative testing of monoclonal antibodies against Plasmodium falciparum sporozoites for ELISA development. Bull World Health Organ 1987, 65:39-45.

18. Martinez-Torres D, Chandre F, Williamson MS, Darriet F, Serge JB, Devonshire AL, Gulliet P, Pasteur N, Pauron D: Molecular characterization of pyrethroid knockdown resistance $(k d r)$ in the major malaria vector Anopheles gambiae s.s. Insect Mol Biol 1998, 7:179-184.

19. Ranson H, Jensen B, Vulule JM, Wang X, Hemingway J, Collins FH: Identification of a point mutation in the voltage-gated sodium channel gene of Kenyan Anopheles gambiae associated with resistance to DDT and pyrethroids. Insect Mol Biol 2000, 9:49|-497.

20. Matambo TS, Abdalla H, Brooke BD, Koekemoer LL, Mnzava A, Hunt $\mathrm{RH}$, Coetzee M: Insecticide resistance in the malaria mosquito Anopheles arabiensis and association with the kdr mutation. Med Vet Entomol 2007, 21 :97-102.

21. The National Center for Biotechnology Information GenBank Database [http://www.ncbi.nlm.nih.gov/Genbank]

22. Weill M, Malcolm C, Chandre F, Mogensen K, Berthomieu A, Marquine $M$, Raymond $M$ : The unique mutation in ace- I giving high insecticide resistance is easily detectable in mosquito vectors. Insect Mol Biol 2004, I 3: I-7.

23. Penilla RP, Rodriguez AD, Hemingway J, Torres JL, Arrendo-Jimenez $\mathrm{Jl}$, Rodriguez $\mathrm{MH}$ : Resistance management strategies in malaria vector control. Baseline data for a large-scale field trial against Anopheles albimanus in Mexico. Med Vet Entomol 1998, 12:217-233. 
24. Kent RJ, Coetzee M, Mharakurwa S, Norris D: Feeding and resting behaviour of the mosquito Anopheles longipalpis in a hyper endemic malaria transmission in southern Zambia. Med Vet Entomol 2006, 20:459-463.

25. Manokore V, Murahwa FC, Chirebvu E: Absence of Insecticide resistance in Anopheles in Anopheles gambiae s.l. (Diptera: Culicidae) after four decades of residual house spraying in Gokwe District, Zimbabwe. J Med Entomol 2000, 37:286-288.

26. Govere J: Report on a mission to Gokwe, Zimbabwe. WHO technical report 2003.

27. Enayati AA, Ranson H, Hemingway J: Insect glutathione transferases and insecticide resistance. Insect Mol Biol 2005, I 4:3-8.

28. Matthiessen P: DDT insecticide residues in Zimbabwean wildlife and their potential impact. Zim Sci News 1985, 19:3-8.

29. Vulule JM, Beach RF, Atieli FC, McAllister JC, Brogdon WG, Rober JM, Mwengi RW, Hawley WA: Elevated oxidase and esterase levels associated with permethrin tolerance in Anopheles gambiae from Kenyan villages using permethrin impregnated nets. Med Vet Entomol 1999, 13:239-244.

30. Brogdon WG, McAllister JC, Corwin AM, Cordon-Rosales C: Oxidase-based DDT-pyrethroid cross-resistance in Guatemalan Anopheles albimanus. Pestic Biochem Physiol 1999, 64:I0I-III.

31. Ellisa N, Mouchet J, Riviere F, Meunier JY, Yao K: Resistance of Anopheles gambiae s.s to pyrethroids in Cote d'Ivoire. Ann Soc Belg Med Trop 1993, 73(4):291-294.

32. Lacey LA, Lacey CM: The medical importance of riceland mosquitoes and their control using alternatives to chemical insecticides. J Am Mosq Control Assoc Suppl 1990, 6(4):762.

33. Diabate A, Baldet T, Chandre F, Dabire R, Simard F, Ouedraogo JB, Guillet $P$, Hougard JM: The role of agricultural use of insecticides in resistance to pyrethroids in Anopheles gambiae s.I. in Burkina Faso. Am J Trop Med Hyg 2002, 67:617-622.

34. Fanello C, Petrarca V, della Torre A: The pyrethroid knock-down resistance gene in the Anopheles gambiae complex in Mali and further indication of incipient speciation within Anopheles gambiae s.s. Insect Mol Biol 2003, I 2:24I-245.

35. Lynd A, Ranson H, McCall PJ, Randle PN, Black CM IV, Walker DE, Donnelly MJ: A simplified high-throughput method for pyrethroid knock-down resistance (kdr) detection in Anopheles gambiae. Malar J 2005, 4:16.

36. Verhaeghen K, Van Bortel M, Roelants P, Backeljau T, Coosemans M: Detection of the East and West African kdr mutation in Anopheles gambiae and Anopheles arabiensis from Uganda using a new assay based on FRET/Melt Curve analysis. Malar 2006, 5:16.

37. Abdalla H, Matambo TS, Koekemoer LL, Mnzava AP, Hunt RH, Coetzee M: Insecticide susceptibility and vector status of natural populations of Anopheles arabiensis from Sudan. Trans $R$ Soc Trop Med Hyg 2008, 102:263-27I.

Publish with Bio Med Central and every scientist can read your work free of charge

"BioMed Central will be the most significant development for disseminating the results of biomedical research in our lifetime. "

Sir Paul Nurse, Cancer Research UK

Your research papers will be:

- available free of charge to the entire biomedical community

- peer reviewed and published immediately upon acceptance

- cited in PubMed and archived on PubMed Central

- yours - you keep the copyright

Submit your manuscript here:

http://www.biomedcentral.com/info/publishing_adv.asp
BioMedcentral 